\title{
Early-age deformation and autogenous cracking risk of slag-limestone filler-cement blended binders
}

\author{
Marwen Bouasker ${ }^{\text {a,* }}$, Nour El Houda Khalifa ${ }^{\text {b }}$, Pierre Mounanga ${ }^{c}$, Nabil Ben Kahla ${ }^{\text {b }}$ \\ ${ }^{a}$ Research Centre on Divided Matter - CRMD, FRE CNRS 3520, 45100 Orléans, France \\ ${ }^{\mathrm{b}}$ Laboratory Systems and Applied Mechanics - LASMAP, BP 743, La Marsa 2078, Tunisia \\ ${ }^{c}$ LUNAM Université, Université de Nantes - IUT Saint-Nazaire, GeM, CNRS UMR 6183, Research Institute in Civil Engineering and Mechanics, France
}

\begin{abstract}
This article presents an experimental comparative study of the early-age behavior of binary and ternary cementitious matrices, combining Portland cement (PC), ground granulated blast furnace slag (BFS) and limestone filler (LF). The objective of this work was to quantify the influence of the composition of various blended binders on their physico-chemical evolution and early-age autogenous cracking risk. For this purpose, measurements of the rate of reactions, chemical shrinkage, autogenous shrinkage in free and restrained conditions and mechanical performances were performed on 12 binders prepared with the same water-to-cementitious materials ratio $(\mathrm{w} / \mathrm{cm}=0.32)$ and various dosages of PC, BFS and LF. The result analysis showed that the dilution effect reduced the early-age chemical shrinkage while the filler effect and the slag reactions tended to accelerate its development after a few hours of hydration. The substitution of PC with BFS and LF also led to both refining the 28-days pore size distribution measured by mercury intrusion and increasing the magnitude of early-age free autogenous shrinkage. However, in spite of their higher autogenous shrinkage potential, the binary and ternary binders very often exhibited later autogenous cracking ages than the control Portland cement paste.
\end{abstract}

\section{Introduction and scientific background}

In recent years, multi-component cementitious binders have received a renewed growing interest from the concrete science community [1-26]. These binders are composed of a binary, ternary or even quaternary combination of Portland cement (PC) and supplementary cementitious materials (SCM) such as filler (quartzite filler - QF; limestone filler - LF) and industrial byproducts/ pozzolanic materials (fly ash - FA; calcined clay - CC; microsilica - $\mu \mathrm{S}$; ground granulated blast furnace slag - BFS; silica fume SF; metakaolin - MK; etc.). The interest for these alternate binders

\footnotetext{
* Corresponding author. Tel.: +332384927 71; fax: +33238417063.

E-mail address: marwen.bouasker@univ-orleans.fr (M. Bouasker).
}

to ordinary PC is usually explained or justified by three principal reasons:

- A reduction of the environmental impacts. The production of cement-based binders incorporating high volumes of recycled industrial waste or byproducts in substitution of ordinary PC is seen as one of the most promising way for the cement and concrete industry to decrease its $\mathrm{CO}_{2}$ emissions $[7,9,27,28]$. This will allow the development of concrete compositions with lower environmental impact [29] and also the reduction of landfill disposal.

- An improvement of long-term performances. Numerous studies showed that the combination of cements with SCM exhibited significant advantages over binary binders and plain PC [5]. Indeed, multi-component cement-based 
binders are well known for their improved long-term strength [5,12,14-20,22-24] and durability $[4,5,10,13,16$, 19,24,26].

- A higher potential cost/benefit ratio. The costs of BFS, FA and LF are significantly lower than that of PC and, when considering the material costs, price differences between the individual components may allow, in some cases, the ternary blended cement binders to compete with ordinary PC [5]. However, the use of expensive mineral admixtures (SF for example) to increase the early-age mechanical properties of ternary binders can rapidly reverse this positive cost/benefit ratio [9].

The mix-design principle of multi-component blended cement binders exploits the synergy that may exist between different types of SCM. This synergy, attributed to both chemical and physical phenomena $[15,22,24,25]$, is reflected in two main effects:

- A complementary effect of mutual compensation of the shortcomings of each mineral addition (for example, in PC-SF--FA blended binder, SF improves the early-age performances of concrete while the later pozzolanic reactions of FA contribute to enhance the properties of the hardened concrete $[5,24])$.

- And an interactive effect between PC and SCM which enables to obtain greater performances than those obtained with the individual effects of each addition used separately [10,24].

Several studies have been conducted to optimize the composition of ternary binders and various combinations of cement with SCMcm have been investigated (PC + BFS + SF $[3,4,9,18,19,26]$; $\mathrm{PC}+\mathrm{FA}+\mathrm{SF} \quad[4,5,9-11,18,19,24] ; \quad \mathrm{PC}+\mathrm{FA}+\mathrm{LF} \quad[8,13,21-23,25]$; $\mathrm{PC}+\mathrm{BFS}+\mathrm{LF}[12,14,21] ; \quad \mathrm{PC}+\mathrm{FA}+\mathrm{BFS}[1,2,19,30] ; \quad \mathrm{PC}+\mathrm{FA}+\mathrm{MK}$ $[13,17,20] ; P C+S F+L F[16])$.

FA and BFS, which are available in large quantities, are the most used SCM in replacement of cement in concrete [28]. Their low reactivity at early age can be mitigated by the incorporation of a third component, SF or LF, in moderate amount. The use of SF is increasingly limited due to its high cost [9] while LF, as the main raw material of PC, is usually available in abundance near cement plants. Recent studies have shown that LF used in low or moderate amount (5-10\%) may improve the early-age reactivity of ternary binders $[21-23,25,31]$ without compromising their mechanical properties [21,22]. The adequate combination of PC, LF and BFS can even lead to higher performances when compared to the binary blended cements and plain PCs [12-14].

The great majority of research works carried out on ternary binders concerned the development of their mechanical properties and durability indicators. Very few studies have been dedicated to their risk of early-age cracking due to the physico-chemical interactions between PC and SCM [32], while this issue is of great importance for a wider use of these types of binders in the concrete building industry. For example, Akkaya et al. found that ternary binder concretes, submitted to drying, cracked earlier than binary binder concretes, due to their lower strength [32].

This study aims to investigate the early-age behavior of binary and ternary binders prepared with PC and various substitution rates of LF and BFS, focusing on the risk of early-age autogenous cracking. The autogenous cracking risk of 12 blended cement pastes prepared with the same water-to-cementitious materials $(\mathrm{w} / \mathrm{cm})$ ratio, equal to 0.32 , and different dosages of PC, BFS and LF was analyzed using the ring test method. In parallel, the physico-chemical and mechanical evolutions of the matrices were characterized. The results were then used to correlate the early-age performances of the binders investigated and their resistance to early-age cracking.

\section{Materials}

A CEM I 52.5 N Portland cement (PC) was used (French standard NF EN 197-1 [33]). Its Blaine fineness was $346 \mathrm{~m}^{2} / \mathrm{kg}$ and it contained 3.3\% by weight of gypsum and $4.8 \%$ by weight of limestone filler. The mass fractions of the main phases of cement, as determined with Bogue formulas, were $70 \%$ of $C_{3} S ; 9 \%$ of $C_{2} S ; 3 \%$ of $C_{3} A$ and $13 \%$ of $\mathrm{C}_{4} \mathrm{AF}$. The main constituents of cement and granulated ground blast furnace slag (BFS) are given in Table 1. The used limestone filler (LF) contained $97.7 \%$ of $\mathrm{CaCO}_{3}$ and its density was $2714 \mathrm{~kg} / \mathrm{m}^{3}$. The particle size distributions (PSD) of PC, BFS and LF are given in Fig. 1.

The pastes were prepared in a mixer of $20 \mathrm{~L}$ capacity. Solid constituents were first mixed for $30 \mathrm{~s}$. Then, the mixing water was introduced and the mixing sequence was continued for $90 \mathrm{~s}$ at low speed and $90 \mathrm{~s}$ at high speed.

The compositions of the various binder pastes are given in Table 2. In the following, the term "binder" or "cementitious materials" refers to the binary or ternary combination of two or three solid constituents (PC, BFS and LF), respectively. The water-to-cementitious materials $(\mathrm{w} / \mathrm{cm})$ mass ratio was equal to 0.32 for all the studied mixtures. This low $w / \mathrm{cm}$ ratio was chosen in order to amplify the self-desiccation phenomenon at early-age and so the risk of autogenous cracking of the matrices.

\section{Testing methods}

An isothermal microcalorimeter TAM Air was used to measure the heat flow of reaction of the binders at early age. For each binder paste, $4 \mathrm{~g}$ specimens were taken at the end of mixing, accurately weighed $( \pm 0.01 \mathrm{~g})$ and placed into two cylindrical flasks. The flasks were then sealed and loaded in the apparatus. The first measurement was acquired about $10 \mathrm{~min}$ after the first contact between the binder and the mixing water. The tests were conducted over the first 5 days of hydration. The curves reported in the article are average curves computed from the test results obtained on two parallel specimens.

The chemical shrinkage was determined using the hydrostatic weighing method [34]. At the end of mixing, two samples of 4$5 \mathrm{~g}$ were introduced into two different cylindrical flasks. The

Table 1

Mass composition (\%) and density of cement (PC) and blast furnace slag (BFS) (Data provided by the supplier).

\begin{tabular}{|c|c|c|}
\hline Constituents & PC & BFS \\
\hline $\mathrm{SiO}_{2}$ & 21.39 & 34.49 \\
\hline $\mathrm{Al}_{2} \mathrm{O}_{3}$ & 3.66 & 13.19 \\
\hline $\mathrm{Fe}_{2} \mathrm{O}_{3}$ & 4.25 & 0.40 \\
\hline $\mathrm{CaO}$ & 64.58 & 41.03 \\
\hline $\mathrm{MgO}$ & 0.96 & 8.21 \\
\hline $\mathrm{MnO}$ & 0.13 & 0.40 \\
\hline $\mathrm{TiO}_{2}$ & 0.16 & 0.88 \\
\hline $\mathrm{K}_{2} \mathrm{O}$ & 0.28 & 0.54 \\
\hline $\mathrm{Na}_{2} \mathrm{O}$ & 0.10 & 0.43 \\
\hline $\mathrm{SO}_{3}$ & 2.63 & 0.10 \\
\hline Density, $\mathrm{kg} / \mathrm{m}^{3}$ & 3200 & 2890 \\
\hline
\end{tabular}

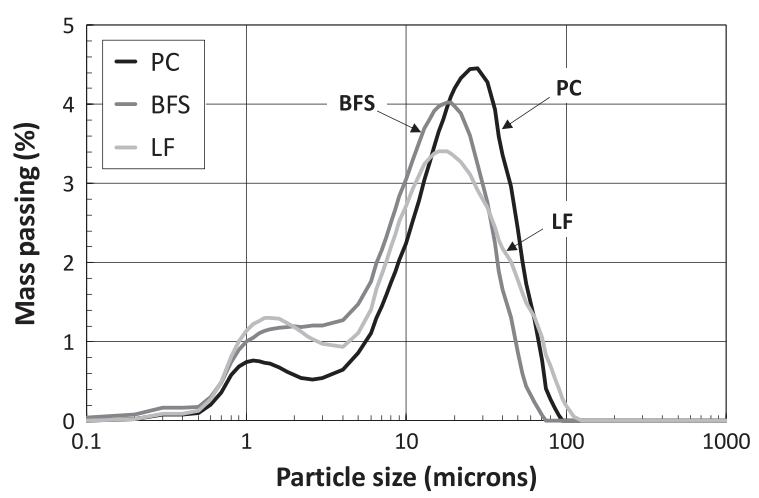

Fig. 1. Particle size distributions for PC, BFS and LF measured by laser granulometry. Results are the average of two individual measurements. 
Table 2

Mass proportion of binary and ternary binders.

\begin{tabular}{llllll}
\hline Labels & PC & BFS & LF & $\mathrm{w} / \mathrm{cm}^{\mathrm{a}}$ & $\mathrm{w} / \mathrm{c}^{\mathrm{b}}$ \\
\hline PC0S0F & 1 & 0 & 0 & 0.32 & 0.32 \\
PC30S0F & 0.7 & 0.3 & 0 & 0.32 & 0.46 \\
PC50S0F & 0.5 & 0.5 & 0 & 0.32 & 0.64 \\
PC80S0F & 0.2 & 0.8 & 0 & 0.32 & 1.60 \\
PC0S10F & 0.9 & 0 & 0.1 & 0.32 & 0.36 \\
PC20S10F & 0.7 & 0.2 & 0.1 & 0.32 & 0.46 \\
PC40S10F & 0.5 & 0.4 & 0.1 & 0.32 & 0.64 \\
PC70S10F & 0.2 & 0.7 & 0.1 & 0.32 & 1.60 \\
PC0S20F & 0.8 & 0 & 0.2 & 0.32 & 0.40 \\
PC10S20F & 0.7 & 0.1 & 0.2 & 0.32 & 0.46 \\
PC30S20F & 0.5 & 0.3 & 0.2 & 0.32 & 0.64 \\
PC60S20F & 0.2 & 0.6 & 0.2 & 0.32 & 1.60 \\
\hline
\end{tabular}

${ }^{\text {a }}$ Water-to-cementitious materials mass ratio.

b Water-to-cement mass ratio.

remaining volume of these flasks was then carefully filled with deaerated water, while avoiding disruption of the samples. Then, each flask was immersed in water and suspended with a nylon thread to a balance (accuracy: $\pm 0.001 \mathrm{~g}$ ). The test system was placed in an air-conditioned room at $20 \pm 2{ }^{\circ} \mathrm{C}$. The data acquisition was started $15 \mathrm{~min}$ after the first contact between the binder and the mixing water and was carried out automatically for $140 \mathrm{~h}$.

The autogenous shrinkage was measured according to the French standard NF P15-433 [35] on $4 \times 4 \times 16 \mathrm{~cm}^{3}$ prismatic specimens stored at $20^{\circ} \mathrm{C}$ and wrapped with several layers of plastic film to avoid evaporation. The first strain measurement was made immediately after the demolding of the specimens, e.g. $24 \mathrm{~h}$ after their casting. For each binder paste, the tests were performed on three specimens.

A quasi-isothermal ring test system [36] was used to study the cracking risk of the pastes. It allowed the monitoring of restrained shrinkage in thermally-controlled conditions. In the present work, the tests were carried out at $20 \pm 1{ }^{\circ} \mathrm{C}$. The experimental set-up was composed of:

- Two concentric rings. The central brass ring, which restrained the deformations of the cement matrix, had an inner diameter of $190 \mathrm{~mm}$, a thickness of $10 \mathrm{~mm}$ and a height of $40 \mathrm{~mm}$. A second outer PVC ring played the role of the external form. The section of the specimen was $40 \times 40 \mathrm{~mm}^{2}$.

- Four strain gauges, which measured the central ring deformations induced by the partially restrained autogenous shrinkage of the pastes, and four additional temperature compensation gauges, stuck on a metal plate attached to the inside face of the central ring.

- A thermal regulation system, made with a network of copper tubes welded to two aluminum plates, which completely covered the lower and upper surfaces of the sample. During the tests, the network of tubes was continuously fed by a thermostated water bath.

Before the beginning of the test, water was circulated through the tubes. When the target water temperature was stabilized, the fresh sample was cast between the two rings and covered with the aluminum top plate to keep it in autogenous conditions. From that moment, the data acquisition was initiated. It was stopped when a through crack appeared in the sample. This resulted in a sudden drop in the strain values of the central ring. For each binder paste, the tests were performed on three specimens.

Additionally, the pore size distribution and the mechanical properties of the pastes were determined [41]. The pore size distribution was measured by mercury intrusion porosimetry (MIP) on 28 day-old specimens ( $7-10 \mathrm{~g}$ ) with an AutoPore IV apparatus
$\left(P_{\max }=400 \mathrm{MPa}\right)$ allowing the investigation of pore radii ranging from $3 \mathrm{~nm}$ up to $1000 \mu \mathrm{m}$. The compressive strength and the dynamic Young's modulus ( $\left.E_{\mathrm{dyn}}\right)$ (apparatus used: Grindosonic ${ }^{\circledR}$ device) were measured on $4 \times 4 \times 16 \mathrm{~cm}^{3}$-specimens stored in autogenous conditions in an air-conditioned room at $20 \pm 2{ }^{\circ} \mathrm{C}$ until the time of testing. For each mix composition, three specimens were tested.

\section{Result analysis}

\subsection{Microphysico-chemical indicators}

\subsubsection{Reaction heat flow}

Fig. 2 presents the heat flow evolution of the different pastes, which was characterized by a hydration peak developing between about $8 \mathrm{~h}$ and $15 \mathrm{~h}$ after the first contact between cementitious materials and mixing water. For an ordinary cement paste, this peak corresponds to the hydration of $\mathrm{C}_{3} \mathrm{~S}$, the major phase of Portland cement $[37,38]$. As expected, the increasing addition of SCM caused a progressive decrease in the intensity of the hydration peak. The systematic reduction in the reaction heat of binary and ternary binders, in comparison with that of the control binder, is clearly shown in Fig. 3, even if this reduction decreased over time,
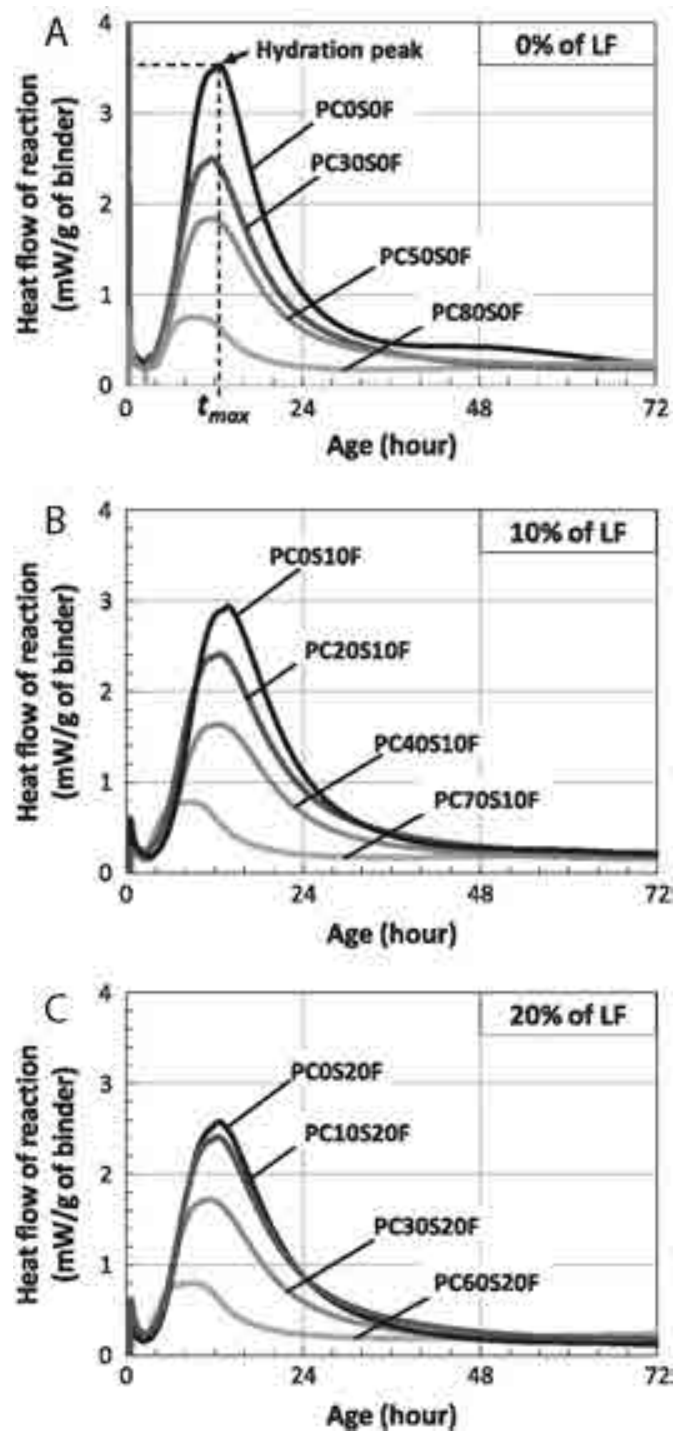

Fig. 2. Reaction heat flow; (A) without LF; (B) with $10 \%$ of LF and (C) with $20 \%$ of LF 


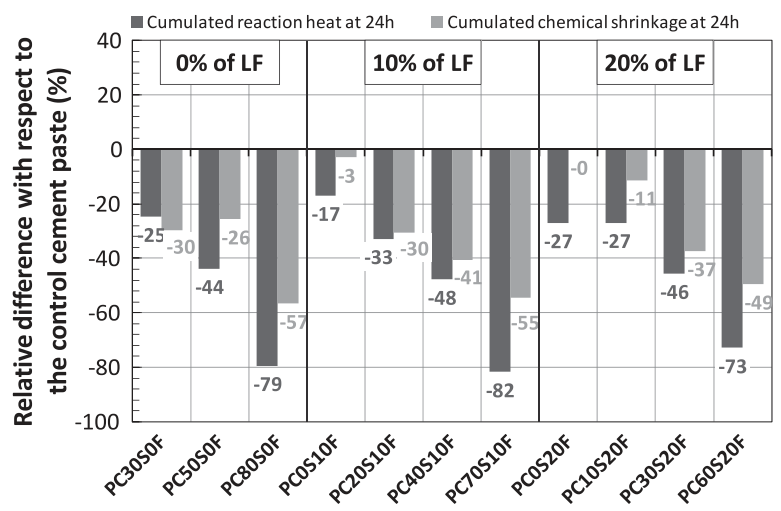

Fig. 3. Relative percentage differences in cumulative heat of reaction and chemical shrinkage at $24 \mathrm{~h}$ with respect to the control mortar.

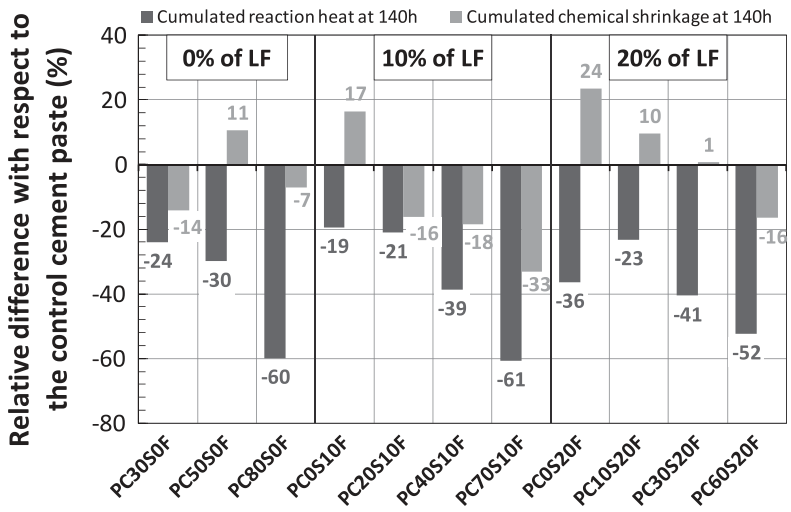

Fig. 4. Relative percentage differences in cumulative heat of reaction and chemical shrinkage at $140 \mathrm{~h}$ with respect to the control mortar.

between 24 and $140 \mathrm{~h}$ (Fig. 4). The lower reaction heat of blended binders may be explained by the quasi-zero reactivity of LF and the lower reaction heat of BFS at very early age, when compared to that of PC $[21,39,40]$. Besides, the need for a basic medium to initiate the hydration of slag makes it react with water more slowly than cement. The dissolution of BFS by the attack of $\mathrm{OH}$-ions present in the pore solution becomes significant when the $\mathrm{pH}$-value of the solution exceeds about 12 [37]. Then the slag reacts with the portlandite produced by the cement hydration, following a pozzolanic process. These two phenomena explain the delayed reaction of the slag.

Regarding the effect of LF, for filler-cement systems, the following two observations can be distinguished:

- A dilution effect before $24 \mathrm{~h}$ of setting (Fig. 2). This figure shows that the substitution of cement by the limestone filler reduces the reaction heat flow [21]. The reaction heat is reduced by $16 \%$ and $27 \%$ by replacing $10 \%$ and $20 \%$ of cement by $L F$ respectively.

- Beyond $24 \mathrm{~h}$, LF begins to participate in the hydration reactions. Indeed, they will serve as additional nucleation sites for hydrates. This effect can be observed on the curve of PCOS10F at $24 \mathrm{~h}$ (Fig. 2B), compared with the PCOSOF at the same curing time (Fig. 2A), where it is noted a slightly increasing in the reaction heat. When the substitution rates reach $20 \%$ of $L F$ (PCOS20F) we note that at $24 \mathrm{~h}$ of hydration, the reaction heat drops to less than $1 \mathrm{~mW} / \mathrm{g}$ binder. This finding is explained by the dominance of the effect of dilution on the second effect (acceleration of the reaction by the additional new nucleation sites).
Regarding the ternary systems we note that the type of substituent (LF or S) has no major effects on the reaction heat flow. Rather, it is the substitution content of the $(L F+S)$ that affects the reaction heat flow at very early age. This observation may support the hypothesis of the dilution effects of the limestone fillers and slag during the calorimeter test investigation.

\subsubsection{Chemical shrinkage}

The experimental curves of chemical shrinkage of the different cement pastes results are provided in Fig. 5. Chemical shrinkage develops because the absolute volume of the hydration products is lower than that of the reactants (cement, SCM and water). It is worth noting that research works carried out on the chemical shrinkage of multi-component binders are very rare [23,34]. De Weerdt et al. observed than LF-PC and LF-FA-PC systems had a slightly higher chemical shrinkage than their limestone free equivalents, demonstrating that in presence of LF, more hydration products were formed, or alternatively different hydrates were produced with less volume than the usual hydrates [23]. The authors also reported that PC blended with FA had a higher total chemical shrinkage per gram of PC, which was attributed to both the filler effect and the later pozzolanic reaction of FA.
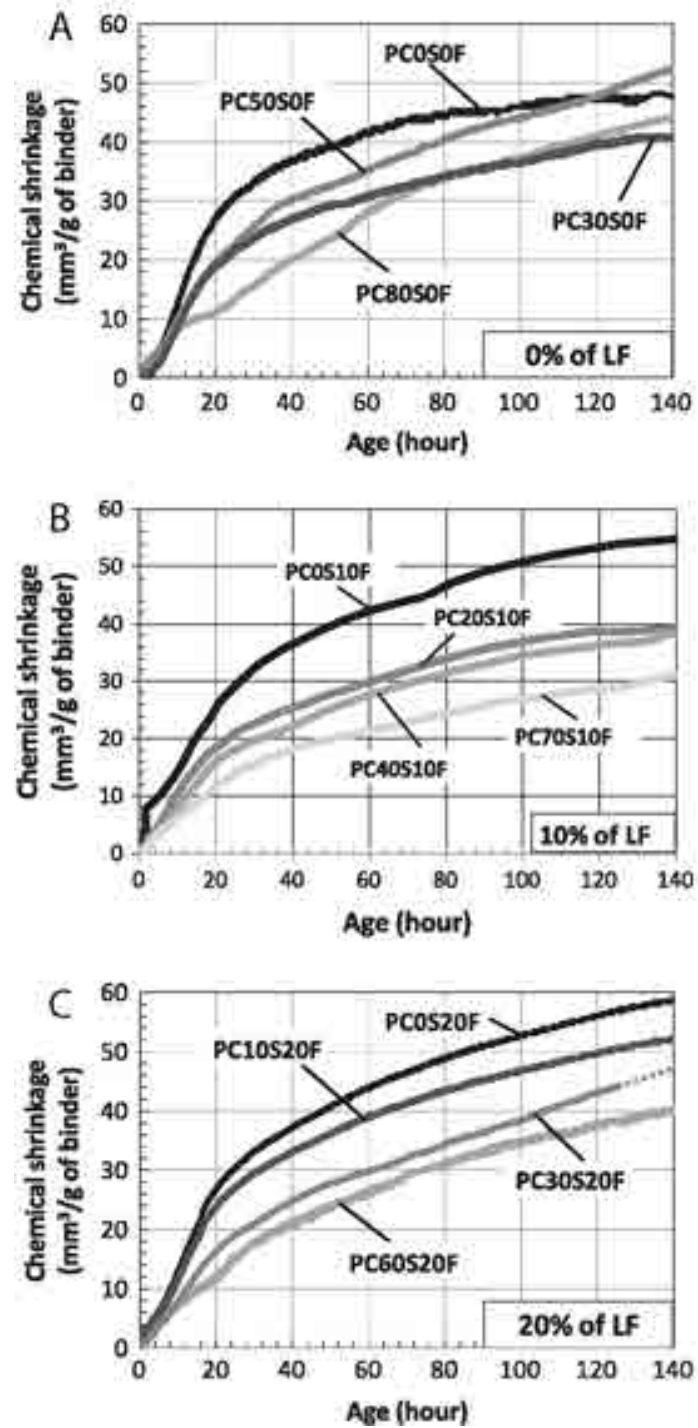

Fig. 5. Chemical shrinkage; (A) without LF; (B) with $10 \%$ of LF and (C) with $20 \%$ of LF. 
The results obtained in the present study confirmed that the partial substitution of cement with LF caused an increase of the early-age chemical shrinkage. PCOS10F and PCOS20F exhibited values of chemical shrinkage $17 \%$ and $24 \%$ higher than that of the control binder (PCOSOF) at $140 \mathrm{~h}$ of hydration, respectively (Fig. 4).

The effect of slag on chemical shrinkage depended on its dosage. For binary binder pastes with $0 \%$ and $30 \%$ of slag, the curves showed a rapid increase during the first $20 \mathrm{~h}$, due to the hydration of PC, followed by a slow deformation phase. The shrinkage of pastes with $50 \%$ and $80 \%$ of slag presented a similar evolution to that of the paste with $30 \%$ of slag during the first hours. At $24 \mathrm{~h}$, PC30S0F, PC50SOF and PC80SOF pastes exhibited chemical shrinkage values lower by $30 \%, 26 \%$ and $57 \%$ than that of the reference paste, respectively. Then (after $24 \mathrm{~h}$ ), the chemical shrinkage evolution rate of the pastes with slag increased (Fig. 5). At $140 \mathrm{~h}$, the difference with the reference paste was reduced to $14 \%$ and $7 \%$ for PC30SOF and PC80SOF pastes, respectively, while the PC50SOF paste even showed higher chemical shrinkage than that of the control binder (Fig. 4). This acceleration resulted in a curve crossing between 80 and $120 \mathrm{~h}$ of hydration and could be explained by the beginning of the slag reactions, which generated additional chemical shrinkage.

This trend was also observed for the ternary binder pastes. The combined effects of slag and filler caused a reduction in the chemical shrinkage of pastes compared to the control cement paste but this difference decreased over time: at $140 \mathrm{~h}$, the chemical shrinkage of PC10S20F and PC30S20F pastes was equal or even higher than that of the control paste.

\subsubsection{Pore size distribution}

The third physico-chemical indicator measured in this study was the pore size distribution of the pastes determined by mercury intrusion porosimetry (MIP). The experimental curves, expressed as the incremental volume vs. pore diameter, are given in Fig. 6.

Two families of pore distributions were clearly highlighted: the pastes with a high slag content (PC80S0F, PC70S10F, PC60S20F) showed a bimodal distribution ranged between [0.009-0.02 $\mu \mathrm{m}]$ and $[0.3-1 \mu \mathrm{m}]$ respectively, while all other pastes had a monomodal distribution centered on a pore diameter of $0.050 \mu \mathrm{m}$. This monomodal distribution was also reported by Baroghel-Bouny et al. [42] in the case of ordinary cement pastes with $w / c=0.25$ and 0.35 and by Ishida et al. [43]. It has been widely reported that the pore size distribution of the BFS matrix was quite different from that of PC [43]. Generally speaking, at very early age, the BFS matrix has a coarse pore structure, while as cement and slag hydration goes on, the BFS matrix exhibits a denser structure than PC and the pore distribution curve of BFS matrices moves towards a much finer diameter. At 28 days, this effect was particularly significant for the higher dosage in slag (Fig. 6).

The addition of filler also tended to refine the porosity of binary binders, with a slightly modification of the total porosity volume, as seen in Fig. 7. Fig. 7 shows a similar evolution of total porosity for the pastes with $0 \%$ and $10 \%$ filler, regardless the slag content. For these pastes, the porosity remained virtually unchanged until $30 \%$ slag content. Between 30\% and 50\% slag, porosity decreased by more than $15 \%$. Beyond $50 \%$ slag, the porosity increased again. For binders with $20 \%$ of limestone filler, an evolution of the porosity different from the binders at $0 \%$ and $10 \%$ limestone filler was observed. Indeed, for the pastes with $20 \%$ limestone filler, the addition of slag up to a dosage of $30 \%$ reduced the porosity; beyond this threshold, the porosity increased again to reach $32 \%$ for $60 \%$ of slag.

\subsubsection{Synthesis on micro-indicators in relation with autogenous volume variations}

The hydration rate, chemical shrinkage and pore size distribution are three key parameters, which determine the rate and
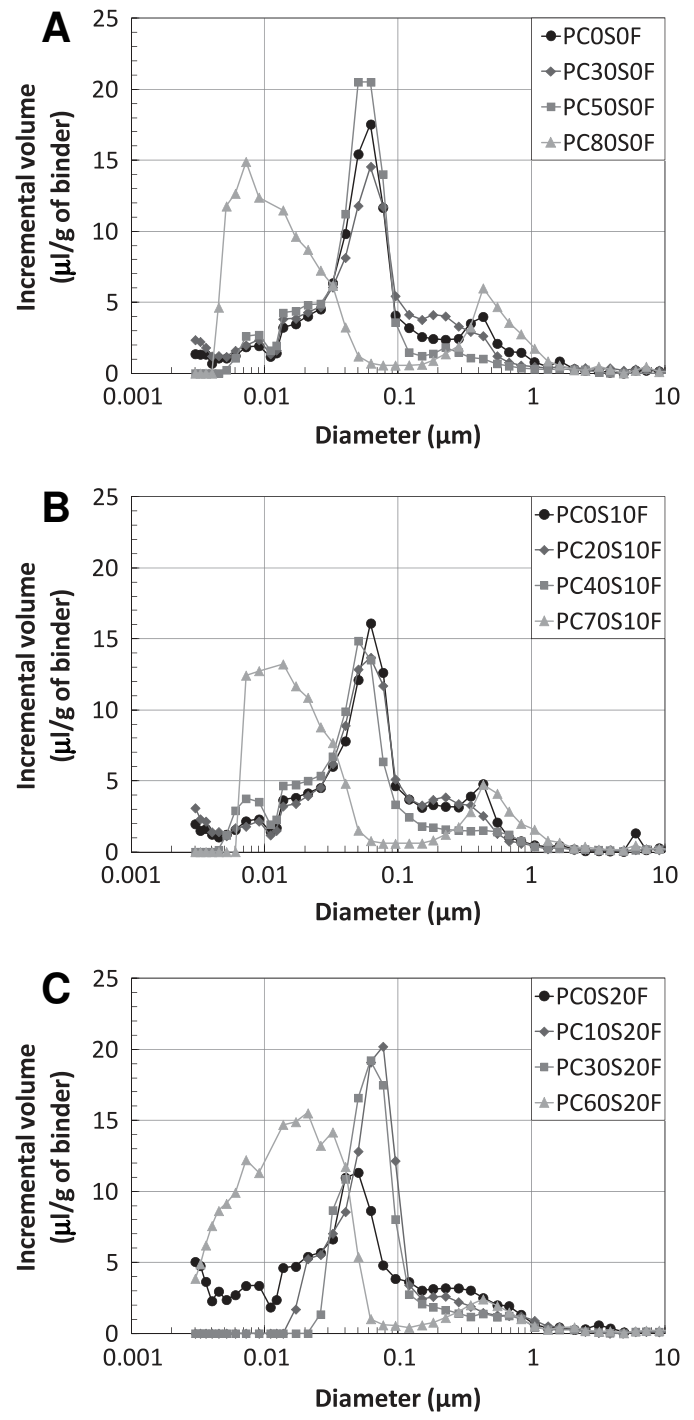

Fig. 6. Mercury porosimetry curves; (A) without LF; (B) with $10 \%$ of LF and (C) with $20 \%$ of LF.

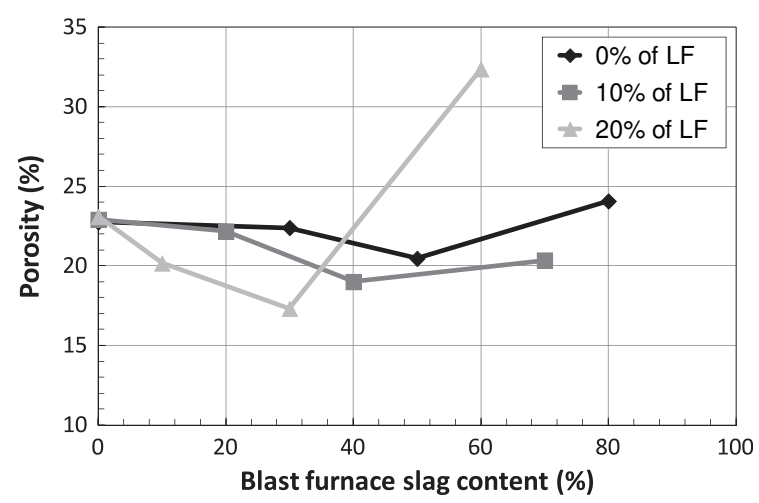

Fig. 7. Total porosity measured by MIP vs.BFS content.

amplitude of the autogenous deformations of cementitious systems, sometimes with opposed effects.

The hydration rate, measured by microcalorimetry, governs the kinetics of water consumption and therefore the rate of de-saturation of the porous network. Overall, the addition of SCM tended to 
increase the early-age reaction rate (quantified as the difference in the time of occurrence between the hydration peak of the blended binder pastes and that of the control paste) and would therefore accelerate the consumption of water, but the dilution effect induced by their presence also increased the effective $\mathrm{w} / \mathrm{c}$ ratio, and therefore limited the effect of self-desiccation at early age. Even if the result of the competition between these two effects (increase of the binder reactivity and increase of the effective $\mathrm{w} / \mathrm{c}$ ratio by dilution effect) depends on the degree of substitution of cement with SCM, it appears that the dilution effect seems predominant; indeed, the relative gain of reactivity caused by the presence of SCM remained low in comparison with the increase of $w / c$ effective ratio due to the dilution effect. For example, the maximal increase in reactivity (reaction rate), observed for the PC70S10F mixture, is $33 \%$, while the $\mathrm{w} / \mathrm{c}$ ratio is multiplied by 5 with respect to that of the control paste. From this point of view, adding SCM will tend to slow down the creation of water menisci within the pores and thus to limit the early-age autogenous deformations.

The chemical shrinkage, the second driving mechanism of selfdesiccation, was also altered by the presence of SCM, as shown in Figs. 3-5. These effects could have two origins: first, the presence of SCM may modify the composition and so the volume occupied by the hydrates formed. Chen and Brouwers [44] calculated that, for full hydration of reactants, the chemical shrinkage of slagblended cement hydration was higher (for $50 \%$ slag, about $12 \mathrm{ml} /$ $100 \mathrm{~g}$ of cement) than that of pure PC (around $8.7 \mathrm{ml} / 100 \mathrm{~g}$ of cement), mainly due to the consumption of portlandite by slag to form hydrates. This could explain the results of this study, showing the progressive increase of chemical shrinkage rate of slag-blended cement pastes. Secondly, by modifying the hydration rate, SCM also influence the chemical shrinkage rate of the matrices; De Weerdt et al. [23] and Bouasker et al. [34] observed higher chemical shrinkage for LF-blended cement matrices, which was attributed to the accelerating effect of LF on PC hydration and the fact that more free water was bound in Ettringite as a result of the influence of LF on cement hydration process $[23,45]$.

In both cases, the acceleration of chemical shrinkage could lead to higher early-age autogenous deformation. This conclusion must be tempered by the fact that the continuous water supply of the chemical shrinkage samples facilitated their hydration and thus the development of their deformation, while in autogenous conditions, the hydration of the binder and so its chemical shrinkage were progressively slowed down as the initial mixing water was consumed. This difference is particularly significant for low $\mathrm{w} / \mathrm{c}$ ratios [46]. In our case, the curing effect was mitigated for binary and ternary binders given the partial replacement of cement with SCM: the effective $\mathrm{w} / \mathrm{c}$ ratio, that is to say the amount of water available for the hydration of cement, was in fact much higher for the binary and ternary binders than for the control binder.

The refinement of porosity caused by the presence of SCM in cement-based matrices may also play a role in the development of autogenous deformation and therefore autogenous cracking. Indeed, according to Laplace law, higher tensile stress in the pore fluid develops in finer pores. It means that, considering the porosimetry results (Fig. 6), the blended binders and particularly those containing the higher dosages in slag will be more prone to develop higher autogenous shrinkage.

\subsection{Macro-mechanical performances: resistance and stiffness}

Before examining the effects of SCM on the autogenous cracking sensitivity of blended binders, the mechanical performances of each binder were analyzed. The evolution of compressive strength and dynamic Young's modulus of the different pastes as a function
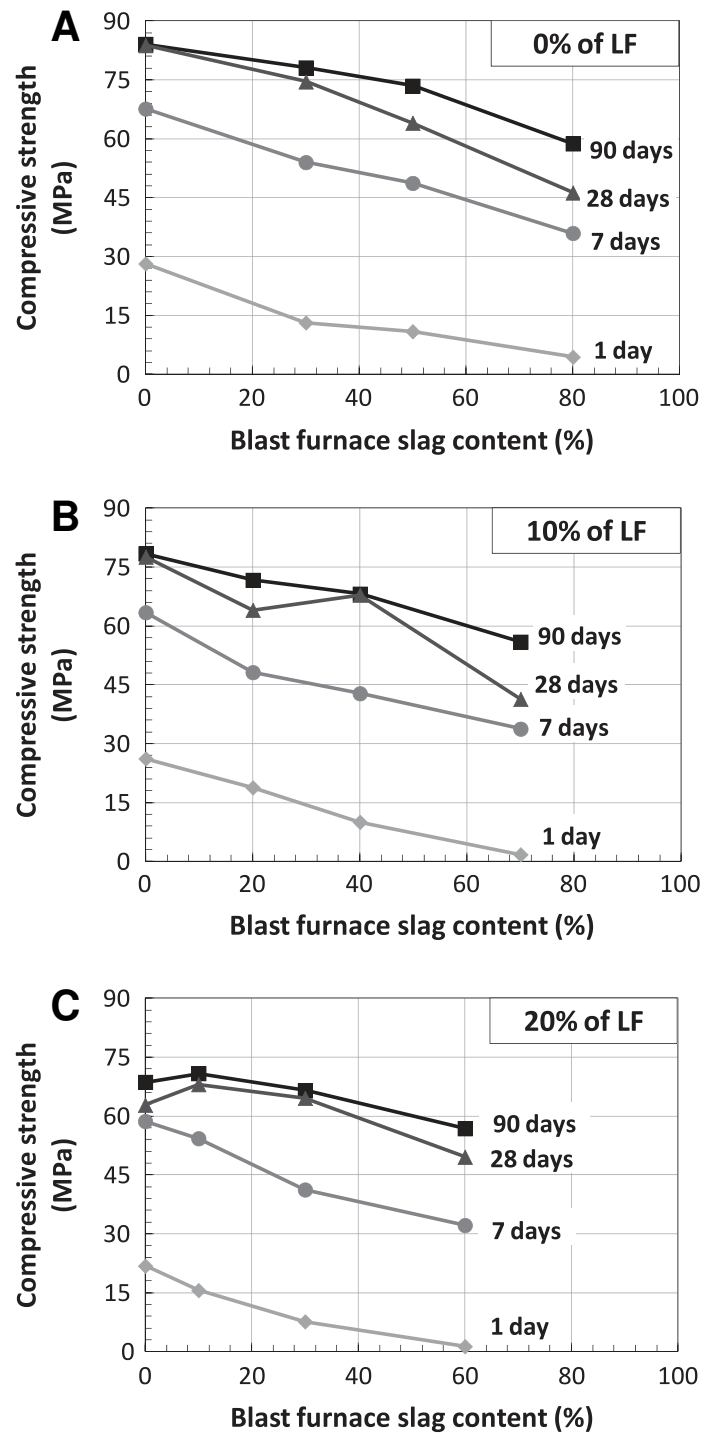

Fig. 8. Compressive strength of the binders vs. BFS content; (A) without LF; (B) with $10 \%$ of LF and (C) with $20 \%$ of LF.

of BFS and LF mass contents are provided in Figs. 8 and 9, respectively.

The partial substitution of PC with BFS and/or LF caused a global reduction of the mechanical performances of the pastes, throughout the whole period of investigation (1-90 days).

As for chemical shrinkage, the strength development of the slag-blended cement pastes was strongly depended on the dosage of BFS. The compressive strength of pastes with a slag dosage of $0 \%$ and $30 \%$ became almost constant beyond 28 days of maturation. For the two other binary slag binders (PC50S0F and PC80S0F), the strength continued to significantly increase between 28 and 90 days. This increase reached $30 \%$ for the cement paste with $80 \%$ of slag. It was explained by the slag contribution in the late hydration reactions [47]. The filler-blended cement binders and the ternary binders ( PC + BFS + LF) also showed systematically lower compressive strength and Young's modulus than those of the pure PC paste.

This reduction in early-age mechanical performances was attributed to the dilution effect induced by the replacement of cement with slag and/or filler. Additionally, the w/c ratio increased in binary and ternary binders due to the reduction of the cement dosage: it was 0.32 for the control binder, and $0.46,0.64$ and 1.60 for 

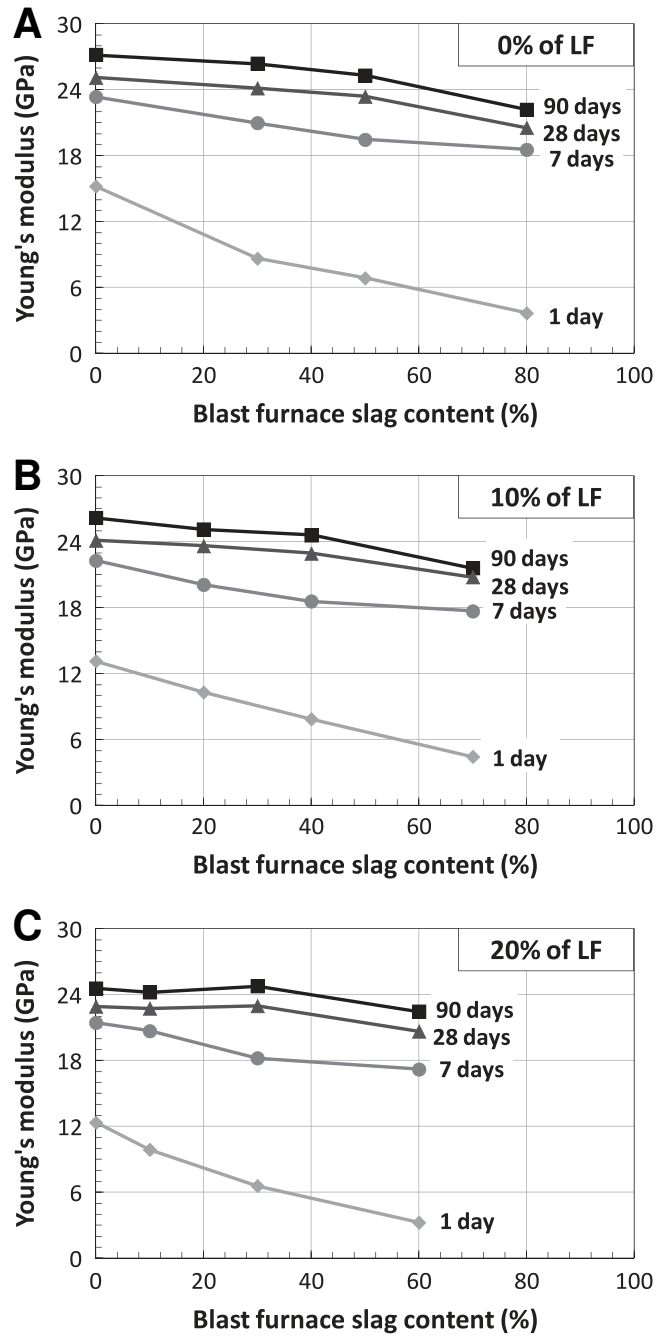

Fig. 9. Dynamic Young's modulus of the binders vs. BFS content; (A) without LF; (B) with $10 \%$ of LF and (C) with $20 \%$ of LF.

cement substitution rate of $30 \%, 50 \%$ and $80 \%$, respectively. Considering the very little contribution of filler to produce hydrates and the low reactivity of slag at early age, the increase of the $\mathrm{w} / \mathrm{c}$ ratio led to a higher porosity volume in blended binder pastes (Fig. 7), and therefore to a lower gain of strength [12].

In some cases, the addition of filler in slag-cement system enabled to enhance the early-age compressive strength of pastes, as reported by Menéndez et al. [12]: for example, at 30\% of cement substitution, the pastes with $20 \%$ of BFS and $10 \%$ of LF (PC20S10LF) and $10 \%$ of BFS and $20 \%$ of LF (PC10S20LF) showed a 1-day compressive strength $43 \%$ and $19 \%$ higher than that of the corresponding binary binder paste (PC30SOLF), respectively. But this effect was only temporary since the compressive strength of PC30SOLF became $14 \%$ and $9 \%$ higher than those of PC20S10LF and PC10S20LF at 28 days. The same tendency was observed for the Young's modulus.

4.3. Effect of additions on early-age free and restrained autogenous shrinkage and cracking

\subsubsection{Free autogenous shrinkage}

For each studied mix composition, the free and partially restrained shrinkage evolutions were measured in autogenous and quasi-isothermal conditions $\left(20 \pm 1^{\circ} \mathrm{C}\right)$. The free shrinkage curves,
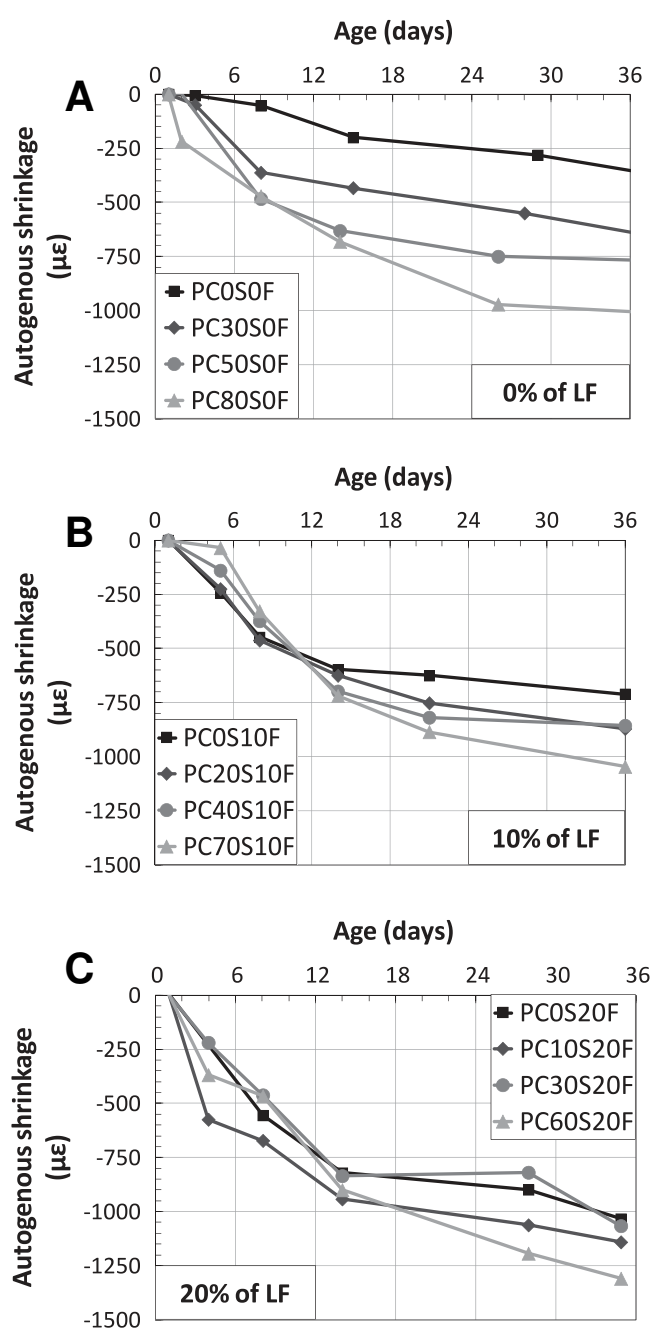

Fig. 10. Free autogenous shrinkage; (A) without LF; (B) with $10 \%$ of LF and (C) with $20 \%$ of LF.

recorded from 1 to 36 days of hydration, are plotted in Fig. 10. The partial substitution of cement with slag caused an increase of autogenous shrinkage. This result is in agreement with previous studies [36,48-52]. Tazawa and Miyazawa [48], and Lee et al. [52] found an increase of autogenous shrinkage as the percentage of cement substituted by slag increased up to $90 \%$ and up to $50 \%$, respectively. Lim and Wee [49] observed that a replacement percentage of $50 \%$ BFS gave larger autogenous shrinkage and that an increase (up to $80 \%$ ) or decrease (down to $30 \%$ ) in the replacement percentage reduced the autogenous shrinkage of concrete [49]. According to the authors, the maximal value of autogenous shrinkage obtained for the $50 \%$ BFS replacement level may be due to a higher degree of hydration, and therefore, a greater degree of self-desiccation.

The increase of autogenous shrinkage of slag-blended cement paste as compared with that of control cement paste, is clearly correlated to the micro-physico-chemical and macro-mechanical properties of the pastes: the higher chemical evolution rate at early-age (recorded between 24 and $140 \mathrm{~h}$ ), the finer porosity (particularly for the higher slag replacement levels) and the lower Young's modulus simultaneously induced a greater self-desiccation of the pore network and a higher capacity of the slag-cement matrix to deform when submitted to self-induced stress. The increase of the effective $\mathrm{w} / \mathrm{c}$ ratio due to the replacement of cement with slag, which could limit the self-desiccation phenomenon, did 
not compensate the effect of slag on chemical shrinkage, pore size, and Young's modulus.

The addition of LF to the slag-cement system had a triple effect on the autogenous shrinkage of ternary binders. The first effect was to slow down the evolution of autogenous shrinkage of the pastes containing the higher dosages in slag, at very early age: indeed, during the first ten days of hydration, the shrinkage of PC40S10F and PC70S10F was lower than that of PCOS10F and PC20S10F. The same observation was made for the PC30S20F and PC60S20F curves, when compared with the PCOS20F and PC10S20F curves. This lower shrinkage rate is probably linked to the higher $\mathrm{w} / \mathrm{c}$ ratio of the systems containing more SCM, which delayed the development of the self-desiccation in the pore network at early-age. The second effect of limestone filler was a progressive reduction of the gap between the shrinkage curves of the ternary binders. It means that, beyond the first ten days of hydration, the autogenous shrinkage of pastes with high dosage of slag increased more rapidly than that of Portland cement paste, due to the later reactions of slag and the development of a finer pore structure. Similar results were observed by Zhou et al. [53] on slag-blended cement pastes after about the first $48 \mathrm{~h}$ of hydration and by Lee et al. [52] and Darquennes et al. [54] on BFS concretes after the first 7 days of hydration. However, at the end of the period of investigation, the relative position of the ternary binder shrinkage curves remained the same as the one observed for the binary pastes, the higher dosage of slag inducing the greater autogenous shrinkage.

The third effect of LF was to increase the "final" amplitude of autogenous shrinkage of the ternary binders, in comparison with the corresponding binary binders. This increase was attributed, as previously mentioned, to the acceleration of chemical shrinkage evolution, the refinement of the porosity and the diminution of the Young's modulus.

\subsubsection{Early-age restrained autogenous shrinkage and cracking}

Free autogenous shrinkage measurements are not sufficient to estimate the sensitivity of the binder to autogenous cracking. Indeed, the autogenous cracking tendency of a cement-based material is the result of the competition between the gain of mechanical resistance to tensile stress, the early-age self-induced stress development due to the partial or total restraint of autogenous deformations, and the capacity of the matrix to relax these stress without significant damage. In order to investigate and compare the risk of early-age autogenous cracking of the binary and the ternary binders, ring tests were performed. The evolutions of the maximal tensile stress, provided in Fig. 11, were obtained from the deformations of the central brass ring, measured during the tests [55]. The moment at which the cracking started was detected by the sharp drop in the ring strain-time curve.

A general observation of the ring test curves reveals that the presence of SCM delayed, to a more or less extent, the age of the first autogenous through crack. Darquennes et al. also observed that the cracking susceptibility of slag cement concretes kept in autogenous conditions was delayed in comparison with Portland cement concrete [54], the higher dosage of slag inducing the higher delay in cracking. They attributed this behavior to the slower hydration rate, the larger capacity to relax tensile stresses and the early-age expansion of slag cement concrete.

The current results show that the cracking age of the matrices depended on the dosage in SCM. For a given dosage in LF, the pastes with the lower slag content (PC30S0F, PC20S10F and PC10S20F) always cracked later. It indicates that for these three mixtures, despite a higher autogenous shrinkage than that of the reference paste (PCOSOF), the combined effects of a reduced Young's modulus and likely higher relaxation capacity delayed the development of internal stresses and thus the age of cracking (from $35 \%$ up to $149 \%$, depending on the slag and filler contents)
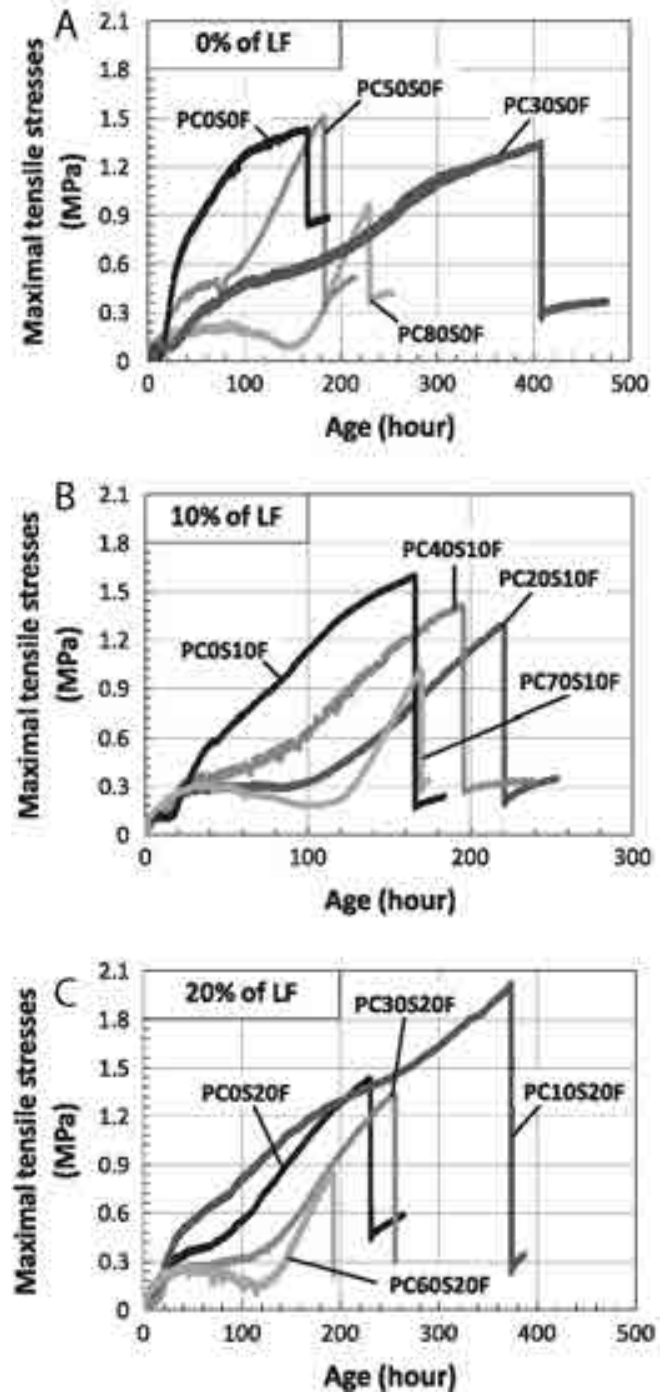

Fig. 11. Cracking ring test curves; (A) without LF; (B) with $10 \%$ of LF and (C) with $20 \%$ of LF.

of the matrices in comparison with those of the reference paste. The maximum tensile stress levels reached at the moment of cracking demonstrated that the tensile strength of the material cannot be considered as a reliable indicator of the autogenous cracking risk. For example, the PC30S0F paste cracked later that the PC10S20F paste, but for a lower stress level. In other words, a higher early-age tensile strength does not guarantee a later age of cracking.

When the content in SCM increased up to $50 \%$ of replacement rate, the cracking age of the blended binder pastes (PC50SOF, PC40S10F and PC30S20F) became close to that of the corresponding reference paste (PCOSOF, PCOS10F and PCOS20F, respectively), while remaining later. The amplification of the deformations associated with the higher dosage in SCM probably accelerates the development of early-age self-induced stresses and explains this shortening of the cracking age.

Increasing the dosage of SCM up to $80 \%$ significantly altered the shape of the ring strain curves, which were characterized by a first increasing phase followed by a decreasing phase indicating a reduction of the pressure exerted on the metal ring. Then, the curves showed an increasing and quasi-linear evolution until the moment of cracking. This phase of decreasing stress indicates either a swelling or a microcracking of the matrix, which could re- 
duce the pressure exerted by the paste, and so the metal ring strain. The rapid growth of strain after the decreasing phase suggests a regime change in the development of the autogenous deformations and corresponds well with both the acceleration of chemical shrinkage observed between 24 and $140 \mathrm{~h}$ and the increasing autogenous shrinkage rate of the matrices containing the higher dosages in SCM. It is worth noting that these binders exhibited also a different and unsystematic behavior concerning their cracking age. For a given LF dosage, they sometimes cracked before the corresponding reference binders (PCOS20F: $230.2 \mathrm{~h}$; PC60S20F: 193.0 h), sometimes after (PCOSOF: 164.8 h; PC80SOF: $229.3 \mathrm{~h}$ ), or almost at the same age (PCOS10F: $165.7 \mathrm{~h}$; PC70S10F: $169.7 \mathrm{~h}$ ) for quite similar stress levels.

For these pastes (PC80S0F, PC70S10F and PC60S20F), the maximal tensile stress reached at the moment of cracking was significantly lower than the control paste: it is $33 \%, 29 \%$ and $41 \%$ lower than that of the PCOSOF paste, respectively, indicating their particularly weak mechanical performances at early age. Further research works at the micro-scale are needed to highlight the microstructural characteristics of these binders: MIP measurement already showed their specific pore size distribution in comparison with the binders with low or moderate SCM dosages but this micro-indicator remains insufficient to clearly understand the earlyage cracking sensitivity of high slag blended cementitious systems.

The substitution of cement with filler also tended to delay the age of the first crack of filler-cement binder. This effect was particularly significant for the paste with $20 \%$ of filler, for which a delay of about $65 \mathrm{~h}$ of the age of cracking was registered, when compared to PCOSOF (age of cracking: $164.8 \mathrm{~h}$ ) and PCOS10F (age of cracking: $165.7 \mathrm{~h}$ ). Considering the higher early-age autogenous shrinkage of LF-PC-cement pastes and the relatively close values of Young's modulus of PCOSOF, PC10SOF and PC20SOF, the explanation to the later cracking of PC20SOF may lie in its higher capacity of stress relaxation, which probably induced a slower evolution of self-induced stress. The first crack occurred at a close stress level for the three pastes considered (PCOSOF, PCOS10F and PCOS20F). The effect of filler on the stress development was therefore primarily a delaying effect: for the substitution rate investigated here, LF did not significantly modify the level of early-age mechanical resistance to tensile stress of the binder.

\section{Conclusions}

The result analysis of this study on the early-age behavior of binary and ternary binders highlighted the following points:

- The partial replacement of Portland cement (PC) with blast furnace slag (BFS) and/or limestone filler (LF) caused a decrease in early-age reaction heat and chemical shrinkage, due to the lower reactivity of the supplementary cementitious materials (SCM). After a few hours of hydration, the filler effect and the starting of the slag reactions tended to accelerate the evolution of both heat of reaction and chemical shrinkage, as indicated by the progressive reduction of the gap between the binary and ternary binder curves and the reference binder one (free of slag and filler).

- As previously reported, the substitution of PC with BFS and/or LF resulted in a decrease in mechanical strength and Young's modulus, when compared to the control binder. For ternary binders with $30 \%$ of cement substitution rate, the addition of filler in slag-cement system does not affect the compressive strength of pastes at later ages.

- The combination of PC, BFS and LF in binary and ternary binders yielded, in most cases, a delay of the cracking ztime compared to the corresponding binary binder paste.
The increase in the dosage of $\mathrm{LF}$ from $10 \%$ to $20 \%$ resulted in delaying the appearance of the first crack in the ternary binders. The best results in terms of crack delaying were obtained for the binders with the lowest concentration of slag. The higher was the slag substitution, the earlier the first cracking of ternary binders tended to occur.

\section{References}

[1] Douglas E, Pouskouleli G. Prediction of compressive strengths of mortars made with portland cement-blast furnace slag-fly ash blends. Cem Concr Res 1991; 21(4):523-34.

[2] Wang D, Chen ZY. On predicting compressive strengths of mortars with ternary blends of cement, GGBFS and fly ash. Cem Concr Res 1997;27(4): 487-93.

[3] Bágel L. Strength and pore structure of ternary blended cement mortars containing blast furnace slag and silica fume. Cem Concr Res 1998;28(7): $1011-20$.

[4] Lane DS, Ozyildirim C. Preventive measures for alkali-silica reactions (binary and ternary systems). Cem Concr Res 1999;29(8):1281-8.

[5] Thomas MDA, Shehata MH, Shashiprakash SG, Hopkins DS, Cail K. Use of ternary cementitious systems containing silica fume and fly ash in concrete. Cem Concr Res 1999;29(8):1207-14.

[6] Khan MI, Lynsdale CJ, Waldron P. Porosity and strength of PFA/SF/OPC ternary blended paste. Cem Concr Res 2000;30(8):1225-9.

[7] Nehdi M. Ternary and quaternary cements for sustainable development. Concr Int 2001;23(4):36-44.

[8] Elkhadiri I, Diouri A, Boukhari A, Aride J, Puertas F. Mechanical behaviour of various mortars made by combined fly ash and limestone in Moroccan Portland cement. Cem Concr Res 2002;32(10):1597-603.

[9] Nehdi ML, Sumner J. Optimization of ternary cementitious mortar blends using factorial experimental plans. Mater Struct 2002;35(8):495-503.

[10] Shehata MH, Thomas MDA. Use of ternary blends containing silica fume and fly ash to suppress expansion due to alkali-silica reaction in concrete. Cem Concr Res 2002;32(3):341-9.

[11] Chen HS, Sun W, Stroeven P. Prediction of compressive strength and optimization of mixture proportioning in ternary cementitious systems. Mater Struct 2003;36(6):396-401.

[12] Menéndez G, Bonavetti V, Irassar EF. Strength development of ternary blended cement with limestone filler and blast-furnace slag. Cem Concr Res 2003; 25(1):61-7.

[13] Pandey SP, Singh AK, Sharma RL, Tiwari AK. Studies on high-performance blended/multiblended cements and their durability characteristics. Cem Concr Res 2003;33(9):1433-6.

[14] Carrasco MF, Menéndez G, Bonavetti V, Irassar EF. Strength optimization of "tailor-made cement" with limestone filler and blast furnace slag. Cem Concr Res 2005;35(7):1324-31.

[15] Antiohos SK, Papadakis VG, Chaniotakis E, Tsimas S. Improving the performance of ternary blended cements by mixing different types of fly ashes. Cem Concr Res 2007;37(6):877-85

[16] Zelić J, Jozić D, Krpan-Lisica D. Synergistic action of a ternary system of Portland cement - limestone - silica fume in concrete. In: Bittnar Z, Bartos P, Němeček J, Šmilauer V, Zeman J, editors. Nanotechnology in Construction 3. Berlin Heidelberg: Springer; 2009. p. 425-34.

[17] Güneyisi E, Gesoğlu M. Properties of self-compacting mortars with binary and ternary cementitious blends of fly ash and metakaolin. Mater Struct 2008; 41(9):1519-31.

[18] Erdem TK, Kirca O. Use of binary and ternary blends in high strength concrete. Constr Build Mater 2008;22(7):1477-83.

[19] Gesoğlu M, Güneyisi E, Özbay E. Properties of self-compacting concretes made with binary, ternary, and quaternary cementitious blends of fly ash, blast furnace slag, and silica fume. Constr Build Mater 2009;23(5):1847-54.

[20] Moser RD, Jayapalan AR, Garas VY, Kurtis KE. Assessment of binary and ternary blends of metakaolin and class C fly ash for alkali-silica reaction mitigation in concrete. Cem Concr Res 2010;40(12):1664-72.

[21] Mounanga P, Khokhar MIA, El Hachem R, Loukili A. Improvement of the earlyage reactivity of fly ash and blast furnace slag cementitious systems using limestone filler. Mater Struct 2011;44(2):437-53.

[22] De Weerdt K, Kjellsen KO, Sellevold E, Justnes H. Synergy between fly ash and limestone powder in ternary cements. Cem Concr Compos 2011;33(1):30-8.

[23] De Weerdt K, Ben Haha M, Le Saout G, Kjellsen KO, Justnes H, Lothenbach B. Hydration mechanisms of ternary Portland cements containing limestone powder and fly ash. Cem Concr Res 2011;41(3):279-91.

[24] Radlinski M, Olek J. Investigation into the synergistic effects in ternary cementitious systems containing portland cement, fly ash and silica fume. Cem Concr Compos 2012:34(4):451-9.

[25] Bentz DP, Sato T, de la Varga I, Weiss WJ. Fine limestone additions to regulate setting in high volume fly ash mixtures. Cem Concr Compos 2012;34(1):11-7.

[26] Bagheri AR, Zanganeh H, Moalemi MM. Mechanical and durability properties of ternary concretes containing silica fume and low reactivity blast furnace slag. Cem Concr Compos 2012;34(5):663-70. 
[27] Mehta PK. Reducing the environmental impact of concrete. Concr Int 2001;23(10):61-6.

[28] Malhotra VM. Reducing $\mathrm{CO}_{2}$ emissions. Concr Int 2006;28(9):42-5.

[29] Damtoft JS, Lukasik J, Herfort D, Sorrentino D, Gartner EM. Sustainable development and climate change initiatives. Cem Concr Res 2008; 38(2):115-27.

[30] Tan K, Pu X. Strengthening effects of finely ground fly ash, granulated blast furnace slag, and their combination. Cem Concr Res 1998;8(12):1819-25.

[31] Gurney L, Bentz DP, Sato T, Weiss WJ. Reducing Set Retardation in High Volume Fly Ash Mixtures with the Use of Limestone: improving constructability for sustainability, Journal of the Transportation Research Board, No. 2290, Concrete Materials, 2012;139-146.

[32] Akkaya Y, Ouyang C, Shah SP. Effect of supplementary cementitious materials on shrinkage and crack development in concrete. Cem Concr Compos 2007; 29(2):117-23.

[33] NF EN 197-1. Cement - Part 1: composition, specifications and conformity criteria for common cements; 2001.

[34] Bouasker M, Mounanga P, Turcry P, Loukili A, Khelidj A. Chemical shrinkage of cement pastes and mortars at very early age: effect of limestone filler and granular inclusions. Cem Concr Compos 2008;30(1):13-22.

[35] NF P 15-433. Methods of testing cement - determination of shrinkage and swelling; 1994.

[36] Mounanga P, Bouasker M, Pertué A, Perronnet A, Khelidj A. Early-age autogenous cracking of cementitious matrices: physico-chemical analysis and micro/macro investigations. Mater Struct 2011;44(4):749-72.

[37] Taylor HFW. Cement chemistry. San Diego: Academic Press Limited; 1990.

[38] Odler I. Hydration, setting and hardening of Portland cement. In: Hewlett PC, editor. Lea's Chemistry of Cement and Concrete. Oxford: Elsevier; 1998. p. 241-97.

[39] Schindler AK, Folliard KJ. Heat of hydration models for cementitious materials. ACI Mater J 2005;102(1):24-33.

[40] Ballim Y, Graham PC. The effects of supplementary cementing materials in modifying the heat of hydration of concrete. Mater Struct 2009:42(6):803-11.

[41] Diamond S. Mercury porosimetry - an inappropriate method for the measurement of pore size distributions in cement-based materials. Cem Concr Res 2000;30(10):1517-25.

[42] Baroghel-Bouny V, Mounanga P, Loukili A, Khelidj A, Rafaï N. Autogenous deformations of cement pastes - Part II: W/C effects, micro-macro correlations, and threshold values. Cem Concr Res 2006;36(1):123-36.
[43] Ishida T, Luan Y, Sagawa T, Nawa T. Modeling of early age behavior of blast furnace slag concrete based on micro-physical properties. Cem Concr Res 2011;41(12):1357-67.

[44] Chen W, Brouwers HJH. The hydration of slag, Part 2: reaction models for blended cement. J Mater Sci 2007;42(2):444-64.

[45] Lothenbach B, Le Saout G, Gallucci E, Scrivener K. Influence of limestone on the hydration of Portland cements. Cem Concr Res 2008;38(6):848-60.

[46] Mounanga P, Khelidj A, Loukili A, Baroghel-Bouny V. Predicting $\mathrm{Ca}(\mathrm{OH})_{2}$ content and chemical shrinkage of hydrating cement pastes using analytical approach. Cem Concr Res 2004;34(2):255-65.

[47] Siddique R. Waste materials and by-products in concrete. 1st ed. Berlin and Heidelberg: Springer-Verlag; 2008. p. 432.

[48] Tazawa E, Miyazawa S. Influence of cement and admixture on autogenous shrinkage of cement paste. Cem Concr Res 1995;25(2):281-7.

[49] Lim SN, Wee TH. Autogenous shrinkage of ground-granulated blast-furnace slag concrete. ACI Mater J 2000;97(5):587-93.

[50] Lura P, van Breugel K, Maruyama I. Effect of curing temperature and type of cement on early-age shrinkage of high-performance concrete. Cem Concr Res 2001:31(12):1867-72.

[51] Jiang Z, Sun Z, Wang P. Autogenous relative humidity change and autogenous shrinkage of high performance cement pastes. Cem Concr Res 2005;35(8): $1539-45$.

[52] Lee KM, Lee HK, Lee SH, Kim GY. Autogenous shrinkage of concrete containing granulated blast-furnace slag. Cem Concr Res 2006;36(7):1279-85.

[53] Zhou J, Ye G, Schlangen E, van Breugel K. Autogenous deformation of Portland cement paste blended with blast furnace slag measured by mini-TSTM. In: Jensen OM, Lura P, Kovler K, editors. Proceedings of the International RILEM Conference on Volume Changes of Hardening Concrete: Testing and Mitigation; 2006. p. 367-374.

[54] Darquennes A, Staquet S, Delplancke-Ogletree M-P, Espion B. Effect of autogenous deformation on the cracking risk of slag cement concretes. Cem Concr Compos 2011;33(3):368-79.

[55] Hossain AB, Weiss J. Assessing residual stress development and stress relaxation in restrained concrete ring specimens. Cem Concr Compos 2004; 26(5):531-40. 